Int. J. Electrochem. Sci., 13 (2018) 3396 - 3406

\title{
SECM Investigation of the Effects of Hydrogen on the Pitting Processes of X70 Carbon Steel in Simulated Soil Solution
}

\author{
Boyu Yuan ${ }^{1}$, Rui Liu', Shuxian Zhao ${ }^{2}$, Liang $\mathrm{Li}^{2}$, Chao Wang ${ }^{2}$ * \\ ${ }^{1}$ Jiangsu Key Laboratory of Advanced Laser Materials and Devices, School of Physics and Electronic \\ Engineering, Jiangsu Normal University, Xuzhou 221116, China \\ 2 Jiangsu Key Laboratory of Green Synthetic Chemistry for Functional Materials, School of Chemistry \\ \& Material Science, Jiangsu Normal University, Xuzhou, 221116, China \\ *E-mail: wangc@jsnu.edu.cn
}

doi: $10.20964 / 2018.04 .36$

Received: 9 December 2017 / Accepted: 7 February 2018 / Published: 6 March 2018

\begin{abstract}
Effects of hydrogen on the dynamic pitting processes of X70 carbon steel in simulated soil solution were investigated by electrochemical methods and scanning electrochemical microscopy (SECM). With increased hydrogen-charged (H-charged) current, corrosion potential shifts negatively and corrosion current increases. A polyaniline microelectrode has been used in SECM to observe the dynamic $\mathrm{pH}$ changes at the electrode / electrolyte interface. The results show that decreased $\mathrm{pH}$ at the interface corresponds to the occurrence of pitting. It can be concluded that hydrogen is absorbed into the $\mathrm{X} 70$ unevenly and reduces interface $\mathrm{pH}$ to induce pitting.
\end{abstract}

Keywords: X70 carbon steel; Polyaniline-modified Pt microelectrode; H-charged; SECM; Pitting

\section{FULL TEXT}

(C) 2018 The Authors. Published by ESG (www.electrochemsci.org). This article is an open access article distributed under the terms and conditions of the Creative Commons Attribution license (http://creativecommons.org/licenses/by/4.0/). 